\title{
Daratumumab, bortezomib, and dexamethasone in relapsed or refractory multiple myeloma: subgroup analysis of CASTOR based on cytogenetic risk
}

Katja Weisel ${ }^{1 *}$, Andrew Spencer ${ }^{2}$, Suzanne Lentzsch ${ }^{3}$, Hervé Avet-Loiseau ${ }^{4}$, Tomer M. Mark ${ }^{5}$, Ivan Spicka ${ }^{6}$, Tamas Masszi ${ }^{7}$, Birgitta Lauri ${ }^{8}$, Mark-David Levin ${ }^{9}$, Alberto Bosi ${ }^{10}$, Vania Hungria ${ }^{11}$, Michele Cavo ${ }^{12}$, Je-Jung Lee ${ }^{13}$, Ajay Nooka ${ }^{14}$, Hang Quach ${ }^{15}$, Markus Munder ${ }^{16}$, Cindy Lee ${ }^{17}$, Wolney Barreto ${ }^{18}$, Paolo Corradini ${ }^{19}$, Chang-Ki Min ${ }^{20}$, Asher A. Chanan-Khann ${ }^{21}$, Noemi Horvath ${ }^{17}$, Marcelo Capra ${ }^{22}$, Meral Beksac ${ }^{23}$, Roberto Ovilla ${ }^{24}$, Jae-Cheol Jo ${ }^{25}$, Ho-Jin Shin ${ }^{26}$, Pieter Sonneveld ${ }^{27}$, Tineke Casneuf ${ }^{28}$, Nikki DeAngelis ${ }^{29}$, Himal Amin ${ }^{30}$, Jon Ukropec ${ }^{31}$, Rachel Kobos ${ }^{30}$ and Maria-Victoria Mateos ${ }^{32}$

\begin{abstract}
Background: Multiple myeloma (MM) patients with high cytogenetic risk have poor outcomes. In CASTOR, daratumumab plus bortezomib/dexamethasone (D-Vd) prolonged progression-free survival (PFS) versus bortezomib/dexamethasone (Vd) alone and exhibited tolerability in patients with relapsed or refractory MM (RRMM).

Methods: This subgroup analysis evaluated D-Vd versus Vd in CASTOR based on cytogenetic risk, determined using fluorescence in situ hybridization and/or karyotype testing performed locally. High-risk patients had t(4;14), t(14;16), and/or del17p abnormalities. Minimal residual disease (MRD; $10^{-5}$ sensitivity threshold) was assessed via the clonoSEQ ${ }^{\oplus}$ assay V2.0. Of the 498 patients randomized, 40 (16\%) in the D-Vd group and 35 (14\%) in the Vd group were categorized as high risk.

Results: After a median follow-up of 40.0 months, D-Vd prolonged median PFS versus Vd in patients with standard (16.6 vs 6.6 months; HR, 0.26; 95\% Cl, 0.19-0.37; $P<0.0001$ ) and high (12.6 vs 6.2 months; HR, $0.41 ; 95 \% \mathrm{Cl}, 0.21-0.83$; $P=0.0106)$ cytogenetic risk. D-Vd achieved deep responses, including higher rates of MRD negativity and sustained MRD negativity versus $V d$, regardless of cytogenetic risk. The safety profile was consistent with the overall population of CASTOR.
\end{abstract}

Conclusion: These updated data reinforce the effectiveness and tolerability of daratumumab-based regimens for RRMM, regardless of cytogenetic risk status.

Trial registration: ClinicalTrials.gov, NCT02136134. Registered 12 May 2014

Keywords: Clinical trials, Multiple myeloma, Myeloma therapy

\footnotetext{
* Correspondence: k.weisel@uke.de

'Department of Oncology, Hematology and Bone Marrow Transplantation

with Section of Pneumology, University Medical Center Hamburg-Eppendorf, Hamburg, Germany

Full list of author information is available at the end of the article
}

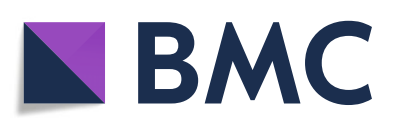

(- The Author(s). 2020 Open Access This article is licensed under a Creative Commons Attribution 4.0 International License, which permits use, sharing, adaptation, distribution and reproduction in any medium or format, as long as you give appropriate credit to the original author(s) and the source, provide a link to the Creative Commons licence, and indicate if changes were made. The images or other third party material in this article are included in the article's Creative Commons licence, unless indicated otherwise in a credit line to the material. If material is not included in the article's Creative Commons licence and your intended use is not permitted by statutory regulation or exceeds the permitted use, you will need to obtain permission directly from the copyright holder. To view a copy of this licence, visit http://creativecommons.org/licenses/by/4.0/. The Creative Commons Public Domain Dedication waiver (http://creativecommons.org/publicdomain/zero/1.0/) applies to the data made available in this article, unless otherwise stated in a credit line to the data. 


\section{Background}

Daratumumab is a human IgGk monoclonal antibody targeting CD38 with a direct on-tumor [1-4] and immunomodulatory mechanism of action [5-7]. Intravenous daratumumab $16 \mathrm{mg} / \mathrm{kg}$ is approved as monotherapy in patients with heavily pre-treated relapsed or refractory multiple myeloma (RRMM) and in combination with bortezomib/dexamethasone (Vd) or lenalidomide/dexamethasone $(\mathrm{Rd})$ in patients with multiple myeloma $(\mathrm{MM})$ who received at least 1 prior line of therapy and in combination with pomalidomide/dexamethasone in patients with at least 2 prior therapies, including lenalidomide and a proteasome inhibitor [8]. Daratumumab is also approved in combination with bortezomib/melphalan/prednisone and in combination with $\mathrm{Rd}$ in patients with transplantineligible newly diagnosed $\mathrm{MM}$, and in combination with bortezomib/thalidomide/dexamethasone in patients with transplant-eligible newly diagnosed MM [8].

In the primary analysis of the phase 3 CASTOR study of daratumumab plus $\mathrm{Vd}(\mathrm{D}-\mathrm{Vd})$ versus $\mathrm{Vd}$ alone in patients with RRMM, at a median follow-up of 7.4 months, D-Vd significantly prolonged progression-free survival (PFS) and increased rates of minimal residual disease (MRD) negativity and demonstrated a tolerable safety profile $[9,10]$. With more than 3 years of follow-up (median 40.0 months) and compared with patients receiving Vd only, patients receiving $\mathrm{D}-\mathrm{Vd}$ demonstrated a $69 \%$ reduction in the risk of disease progression or death (median PFS, 16.7 months vs 7.1 months; hazard ratio [HR], 0.31; 95\% confidence interval [CI], 0.25-0.40; $P<0.0001$ ); showed significantly better overall response rates $(85 \%$ vs $63 \%$; $P<0.0001)$; and achieved better rates of complete response (CR) or better (30\% vs $10 \% ; P<0.0001)$, very good partial response (VGPR) or better (63\% vs 29\%; $P<0.0001)$, and MRD negativity at the $10^{-5}$ sensitivity threshold ( $14 \%$ vs $2 \%$; $P<0.000001)$ [11]. Patients who received 1 prior line of therapy demonstrated the greatest benefit with $\mathrm{D}-\mathrm{Vd}$, including a $78 \%$ reduction in the risk of disease progression or death versus Vd (median PFS, 27.0 months vs 7.9 months; $\mathrm{HR}, 0.22$; $95 \% \mathrm{CI}, 0.15-0.32$; $P<0.0001)$ and a response of CR or better (43\% vs $15 \%$; $P<0.0001)$ and MRD negativity $\left(10^{-5} ; 20 \%\right.$ vs $3 \%$; $P=0.000025)$. In CASTOR, no new safety concerns were observed with longer follow-up [11].

Patients with $\mathrm{MM}$ and specific cytogenetic markers are at higher risk for poor outcomes [12,13]. The International Myeloma Working Group recommends defining high cytogenetic risk as testing positive for at least 1 of the following abnormalities: $t(4 ; 14), t(14 ; 16)$, or del17p, determined by fluorescence in situ hybridization (FISH) [14]. This subgroup analysis of CASTOR presents updated efficacy and safety findings for D-Vd versus Vd treatment based on cytogenetic risk status after a median follow-up of 40.0 months.

\section{Methods}

\section{Patients}

Complete study methodology and primary results from CASTOR have been previously described $[9,15]$. Briefly, eligible patients received at least 1 prior line of $M M$ therapy, with at least a partial response to at least 1 prior MM therapy, and had documented progressive disease during or after their last regimen, as defined by the International Myeloma Working Group criteria [16, 17]. Key exclusion criteria included the following: creatinine clearance $\leq 20 \mathrm{~mL} / \mathrm{min} / 1.73 \mathrm{~m}^{2}$ body surface area, disease refractory or intolerant to bortezomib, disease refractory to a different proteasome inhibitor, or presence of grade $\geq 2$ peripheral neuropathy or neuropathic pain.

\section{Study design and treatment}

CASTOR is a multicenter, randomized, open-label, activecontrolled, phase 3 trial enrolling patients with RRMM. Randomization was stratified by the International Staging System (stage I, II, or III) at screening, the number of prior lines of therapy ( 1 vs 2 or 3 vs $>3$ ), and previous bortezomib treatment (no vs yes). The study protocol was approved by an independent ethics committee or institutional review board at each study center and was conducted in accordance with the principles of the Declaration of Helsinki and the International Conference on Harmonisation Good Clinical Practice guidelines. All patients provided written informed consent.

Patients were randomly assigned $1: 1$ to receive $\mathrm{D}-\mathrm{Vd}$ or Vd. All patients received eight 21-day cycles of Vd. Bortezomib $\left(1.3 \mathrm{mg} / \mathrm{m}^{2}\right)$ was administered subcutaneously on days $1,4,8$, and 11 during cycles 1 through 8 . Dexamethasone $(20 \mathrm{mg})$ was given orally or intravenously on days $1,2,4,5,8,9,11$, and 12 during cycles 1 through 8 . Daratumumab $(16 \mathrm{mg} / \mathrm{kg})$ was administered intravenously to patients in the D-Vd group once weekly during cycles 1 through 3 , once every 3 weeks during cycles 4 through 8 , and once every 4 weeks thereafter until disease progression. Patients in the Vd group were to receive a maximum of 8 cycles of $\mathrm{Vd}$ followed by observation until disease progression; following the primary analysis, patients whose disease progressed could choose to receive daratumumab monotherapy.

\section{Cytogenetic risk}

Cytogenetic risk was evaluated using local FISH or karyotyping. Determination of each abnormality and threshold of frequencies to consider a positive finding was determined locally and varied by site. Patients in the intent-to-treat (ITT) population who had at least $1 \mathrm{FISH}$ or karyotyping assessment were included in the analysis. High-risk patients were defined as having 1 or more of the following cytogenetic abnormalities identified: $\mathrm{t}(4 ; 14), \mathrm{t}(14 ; 16)$, or del17p. 
Table 1 Patient demographics, baseline disease, and clinical characteristics

\begin{tabular}{|c|c|c|c|c|}
\hline \multirow[b]{2}{*}{ Characteristic } & \multicolumn{2}{|c|}{ Standard cytogenetic risk $\mathrm{k}^{\mathrm{a}}$} & \multicolumn{2}{|c|}{ High cytogenetic risk ${ }^{\mathrm{a}, \mathrm{b}}$} \\
\hline & $\mathrm{D}-\mathrm{Vd}(n=141)$ & $\mathrm{Vd}(n=140)$ & $\overline{D-V d}(n=40)$ & $\mathrm{Vd}(n=35)$ \\
\hline \multicolumn{5}{|l|}{ Age, years } \\
\hline Median (range) & $64(40-88)$ & $64(33-85)$ & $63(37-79)$ & $59(37-81)$ \\
\hline$\geq 75$ years, $n(\%)$ & $9(6)$ & $20(14)$ & $4(10)$ & $5(14)$ \\
\hline \multicolumn{5}{|l|}{ Sex, $n(\%)$} \\
\hline Male & $79(56)$ & $89(64)$ & $22(55)$ & $18(51)$ \\
\hline \multicolumn{5}{|l|}{ Race, $n(\%)$} \\
\hline White & $123(87)$ & $123(88)$ & $33(83)$ & $31(89)$ \\
\hline Black or African American & $9(6)$ & $2(1)$ & $1(3)$ & 1 (3) \\
\hline Asian & $8(6)$ & $8(6)$ & $4(10)$ & $2(6)$ \\
\hline Native Hawaiian or other Pacific Islander & $1(1)$ & 0 & 0 & 0 \\
\hline Other & 0 & $1(1)$ & 0 & 0 \\
\hline Unknown/not reported & 0 & $6(4)$ & $2(5)$ & 1 (3) \\
\hline \multicolumn{5}{|l|}{ ISS stage, $n(\%)^{c}$} \\
\hline 1 & $48(34)$ & $55(39)$ & $22(55)$ & $14(40)$ \\
\hline$\|$ & $57(40)$ & $56(40)$ & $11(28)$ & $16(46)$ \\
\hline III & $36(26)$ & $29(21)$ & $7(18)$ & $5(14)$ \\
\hline \multicolumn{5}{|l|}{ ECOG performance status score, $n(\%)$} \\
\hline 0 & $54(38)$ & $64(46)$ & $16(40)$ & $15(43)$ \\
\hline 1 & $78(55)$ & $62(44)$ & $22(55)$ & $19(54)$ \\
\hline 2 & $9(6)$ & $14(10)$ & $2(5)$ & 1 (3) \\
\hline \multicolumn{5}{|l|}{ Cytogenetic profile, $n(\%)^{\mathrm{a}, \mathrm{b}}$} \\
\hline $\mathrm{t}(4 ; 14)$ & - & - & $13(33)$ & $15(43)$ \\
\hline$t(14 ; 16)$ & - & - & $4(10)$ & $5(14)$ \\
\hline del17p & - & - & $27(68)$ & $20(57)$ \\
\hline$\geq 2$ risk factors ${ }^{d}$ & - & - & $4(10)$ & $4(11)$ \\
\hline Median (range) time from diagnosis, years & $4.3(0.7-20.7)$ & $3.6(0.6-18.6)$ & $3.3(1.0-10.5)$ & $3.7(1.0-14.8)$ \\
\hline \multicolumn{5}{|l|}{ Prior lines of therapy, $n(\%)$} \\
\hline 1 & $70(50)$ & $67(48)$ & $21(53)$ & $12(34)$ \\
\hline 2 & $32(23)$ & $40(29)$ & $11(28)$ & $15(43)$ \\
\hline 3 & $25(18)$ & $16(11)$ & $5(13)$ & $6(17)$ \\
\hline$>3$ & $14(10)$ & $17(12)$ & $3(8)$ & $2(6)$ \\
\hline Median (range) & $2(1-9)$ & $2(1-10)$ & $1(1-6)$ & $2(1-4)$ \\
\hline Prior ASCT, $n(\%)$ & $90(64)$ & $79(56)$ & $27(68)$ & $21(60)$ \\
\hline Prior Pl, $n(\%)$ & $101(72)$ & $94(67)$ & $27(68)$ & $28(80)$ \\
\hline Bortezomib & $98(70)$ & $89(64)$ & $25(63)$ & $26(74)$ \\
\hline Prior IMiD, $n(\%)$ & $104(74)$ & $110(79)$ & $28(70)$ & $29(83)$ \\
\hline Lenalidomide & $52(37)$ & $66(47)$ & $15(38)$ & $17(49)$ \\
\hline Prior PI + IMiD, $n(\%)$ & $73(52)$ & $67(48)$ & $15(38)$ & $22(63)$ \\
\hline Refractory to PI only, n (\%) & $1(1)$ & $2(1)$ & $2(5)$ & $1(3)$ \\
\hline Refractory to IMiD only, $n(\%)$ & $41(29)$ & $51(36)$ & $12(30)$ & $11(31)$ \\
\hline Refractory to PI and IMiD, $n(\%)$ & $6(4)$ & $2(1)$ & 0 & $4(11)$ \\
\hline Refractory to last line of therapy, $n(\%)$ & $40(28)$ & $48(34)$ & $11(28)$ & $14(40)$ \\
\hline
\end{tabular}

D-Vd daratumumab/bortezomib/dexamethasone, Vd bortezomib/dexamethasone, ISS International Staging System, ECOG Eastern Cooperative Oncology Group, ASCT autologous stem cell transplantation, PI proteasome inhibitor, IMiD immunomodulatory drug, FISH fluorescence in situ hybridization

Note: percentages may not equal $100 \%$ due to rounding

a Based on FISH/karyotype testing

${ }^{b}$ Patients with high cytogenetic risk had a $t(4 ; 14), t(14 ; 16)$, or del17p abnormality

'ISS stage is derived based on the combination of serum $\beta 2$-microglobulin and albumin

dPatients with $\geq 2$ of the $t(4 ; 14), t(14 ; 16)$, or del17p risk factors 


\section{MRD evaluation}

MRD was evaluated at the time of the suspected CR (including stringent $\mathrm{CR}$; blinded to treatment group) and at 6 and 12 months after the first treatment dose (i.e., at the end of $\mathrm{Vd}$ therapy and 6 months later, respectively). Additional MRD evaluations were required every 12 months after CR. MRD was evaluated by nextgeneration sequencing using the clonoSEQ ${ }^{\circ}$ assay V2.0 (Adaptive Biotechnologies, Seattle, WA, USA) at a sensitivity threshold of $10^{-5}$ ( 1 cancer cell per 100,000 nucleated cells). Patients were considered MRD positive if they had an MRD-positive or indeterminate test result or were not assessed. Sustained MRD negativity was defined as maintenance of MRD negativity at the $10^{-5}$ sensitivity threshold for at least 6 months or at least 12 months.

\section{Statistical analyses and assessments}

The primary endpoint of the study was PFS. Exploratory analyses were performed for subgroups of patients based on cytogenetic risk status. PFS was assessed in patients in the ITT population who met the biomarker criteria for risk assessment. The response-evaluable analysis set included patients who had measurable disease at the baseline or screening visit and who received at least 1 study treatment and had at least 1 post-baseline disease assessment. The safety population comprised individuals who received at least 1 administration of study treatment.

PFS and time to response were compared between the D-Vd and Vd groups using a stratified log-rank test. A Cox proportional hazards model was used to estimate HRs and 95\% CIs, with treatment as the sole explanatory variable. The Kaplan-Meier method was used to estimate distributions. PFS on the subsequent line of therapy (PFS2) was defined as the time from randomization to progressive disease after the next line of subsequent therapy or death. Differences between treatment groups for overall response rates, VGPR or better rates, and CR or better rates were measured by a stratified CochranMantel-Haenszel chi-square test.

Patients in the ITT population who met the biomarker criteria for risk assessment were evaluated for MRD and sustained MRD negativity to allow for stringent and unbiased evaluation. MRD-negativity rates were defined as the proportions of patients achieving MRD-negative status at any time after the first treatment dose and were compared between the D-Vd and Vd treatment groups using a Fisher's exact test.

\section{Results}

\section{Patients and treatments}

A total of 498 patients were randomized, with 251 assigned to D-Vd and 247 assigned to $\mathrm{Vd}$. A total of 356 (71\%) patients underwent cytogenetic testing; 283 (57\%) patients were evaluated using FISH, 217 (44\%) patients were evaluated using karyotyping, and 144 (29\%) were evaluated using both. Of these, $40(16 \%)$ patients in the $\mathrm{D}-\mathrm{Vd}$ group and 35 (14\%) patients in the Vd group had high cytogenetic risk abnormalities. Forty of 158 patients in the $\mathrm{D}-\mathrm{Vd}$ group and 35 of 173 patients in the $\mathrm{Vd}$ group who underwent FISH testing were defined as high risk. Two of 130 patients in the D-Vd group and 1 of 136 patients in the $\mathrm{Vd}$ group who underwent karyotype testing were defined as high risk. A total of 141 (56\%) patients in the D-Vd group and 140 (57\%) patients in the Vd group had standard cytogenetic risk. Patient demographics, baseline disease, and clinical characteristics stratified by cytogenetic risk status are shown in Table 1. Among patients achieving CR or better, MRD was not evaluated in $15(16 \%)$ patients. Overall, 170 $(62 \%)$ and $50(68 \%)$ patients in the standard and high cytogenetic risk subgroups discontinued the treatment, respectively (Table 2). Among patients who received Vd

Table 2 Patient disposition based on cytogenetic risk status

\begin{tabular}{|c|c|c|c|c|}
\hline \multirow[b]{2}{*}{ Treatment discontinuation, $n(\%)^{c}$} & \multicolumn{2}{|c|}{ Standard risk ${ }^{a}$} & \multicolumn{2}{|c|}{ High risk ${ }^{a, b}$} \\
\hline & $\mathrm{D}-\mathrm{Vd}(n=137)$ & $\mathrm{Vd}(n=136)$ & $\mathrm{D}-\mathrm{Vd}(n=40)$ & $\mathrm{Vd}(n=34)$ \\
\hline Patients who discontinued treatment & $108(79)$ & $62(46)$ & $33(83)$ & $17(50)$ \\
\hline \multicolumn{5}{|l|}{ Reason for discontinuation } \\
\hline Progressive disease & $86(63)$ & $34(25)$ & $27(68)$ & $12(35)$ \\
\hline Adverse event & $11(8)$ & $15(11)$ & $5(13)$ & $3(9)$ \\
\hline Noncompliance with study drug ${ }^{d}$ & $5(4)$ & $5(4)$ & 0 & $1(3)$ \\
\hline Withdrawal by patient & $1(1)$ & $6(4)$ & 0 & $1(3)$ \\
\hline Death & $2(1)$ & $2(1)$ & $1(3)$ & 0 \\
\hline Physician decision & $3(2)$ & 0 & 0 & 0 \\
\hline
\end{tabular}

$D$-Vd daratumumab/bortezomib/dexamethasone, $V d$ bortezomib/dexamethasone, FISH fluorescence in situ hybridization

a Based on FISH/karyotyping

${ }^{b}$ Patients with high cytogenetic risk had a $t(4 ; 14), t(14 ; 16)$, or del17p abnormality

'Safety population

dBased on reason "Patient refused to further study treatment" at "End of treatment" 
and discontinued treatment due to progressive disease, 9 of 34 and 2 of 12 patients in the standard and high cytogenetic risk subgroups, respectively, received daratumumab monotherapy as subsequent therapy.

\section{Updated efficacy results}

After a median follow-up of 40.0 months, treatment with $\mathrm{D}-\mathrm{Vd}$ prolonged median PFS compared with $\mathrm{Vd}$ alone in patients with standard cytogenetic risk (16.6 months vs 6.6 months; HR, 0.26; 95\% CI, 0.19-0.37; $P<0.0001$; Fig. 1a) as well as high cytogenetic risk (12.6 months vs 6.2 months; HR, 0.41; 95\% CI, 0.21-0.83; $P=0.0106$; Fig. 1 b) in the ITT population. Among a subset of patients who had received 1 prior line of therapy, treatment with $\mathrm{D}-\mathrm{Vd}$ prolonged median PFS versus Vd in patients with standard cytogenetic risk (29.8 months vs 7.5 months; HR, 0.25 ; 95\% CI, $0.15-$ $0.42 ; P<0.0001$; Fig. 1c) and high cytogenetic risk
(20.1 months vs 8.4 months; HR, 0.20; 95\% CI, 0.06-0.62; $P=0.0026$; Fig. 1d).

Higher overall response rate was achieved with $\mathrm{D}-\mathrm{Vd}$ versus $\mathrm{Vd}$ (standard risk, $84 \%$ vs $62 \% ; P<0.0001$; high risk, $85 \%$ vs $56 \% ; P=0.0512$ ), including deep responses of CR or better (standard risk, $28 \%$ vs $10 \%$; high risk, $28 \%$ vs $6 \%$ ) and VGPR or better (standard risk, $62 \%$ vs $28 \% ; P<0.0001$; high risk, $59 \%$ vs $32 \% ; P=0.1259$; Table 3). Median time to VGPR or better was decreased with $\mathrm{D}-\mathrm{Vd}$ compared with $\mathrm{Vd}$ in patients with standard cytogenetic risk (3.5 months vs not estimable; HR, 2.16; 95\% CI, 1.46-3.20; $P<0.0001)$ and high cytogenetic risk (3.5 months vs 6.2 months; HR, 1.96; 95\% CI, 0.86-4.45; $P=0.1004)$.

Rates of MRD negativity at the $10^{-5}$ sensitivity threshold were higher with $\mathrm{D}-\mathrm{Vd}$ compared with $\mathrm{Vd}$ in patients with standard cytogenetic risk ( $11 \%$ vs $3 \%$;

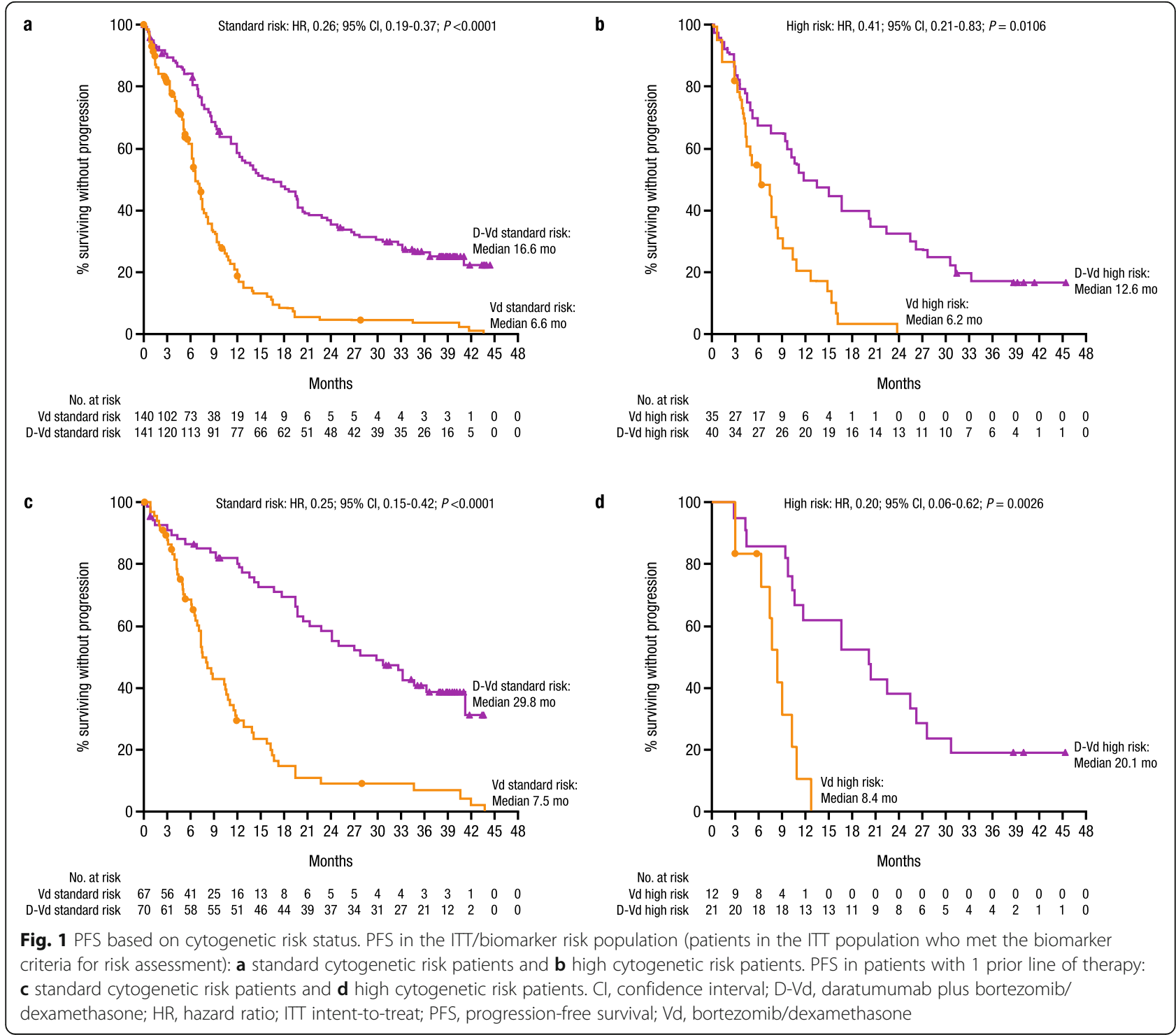


Table 3 Response and MRD-negativity rates in patients with standard and high cytogenetic risk

\begin{tabular}{|c|c|c|c|c|c|c|}
\hline \multirow[b]{2}{*}{ Response, $n(\%)^{\mathrm{b}}$} & \multicolumn{3}{|c|}{ Standard risk } & \multicolumn{3}{|c|}{ High risk ${ }^{a}$} \\
\hline & $\mathrm{D}-\mathrm{Vd}(n=135)$ & $\mathrm{Vd}(n=134)$ & $P$ value & $\mathrm{D}-\mathrm{Vd}(n=39)$ & $\mathrm{Vd}(n=34)$ & $P$ value \\
\hline$\overline{\text { ORR }}$ & $113(84)$ & $83(62)$ & $<0.0001$ & $33(85)$ & $19(56)$ & 0.0512 \\
\hline$\geq \mathrm{CR}^{\mathrm{C}}$ & $38(28)$ & $13(10)$ & & $11(28)$ & $2(6)$ & \\
\hline$s C R$ & $12(9)$ & $3(2)$ & & $4(10)$ & 0 & \\
\hline$C R$ & $26(19)$ & $10(8)$ & & $7(18)$ & $2(6)$ & \\
\hline$\geq \mathrm{VGPR}^{\mathrm{d}}$ & $83(62)$ & $38(28)$ & $<0.0001$ & $23(59)$ & $11(32)$ & 0.1259 \\
\hline VGPR & $45(33)$ & $25(19)$ & & $12(31)$ & $9(27)$ & \\
\hline PR & $30(22)$ & $45(34)$ & & $10(26)$ & $8(24)$ & \\
\hline \multicolumn{7}{|l|}{ MRD negative $\left(10^{-5}\right)^{\mathrm{e}}$} \\
\hline$n(\%)$ & $16(11)$ & $4(3)$ & 0.0091 & $6(15)$ & 0 & 0.0271 \\
\hline Sustained MRD negativity ( $\geq 6$ months), $n$ (\%) & $9(6)$ & $3(2)$ & 0.1374 & $5(13)$ & 0 & 0.0569 \\
\hline Sustained MRD negativity ( $\geq 12$ months), $n$ (\%) & $2(1)$ & 0 & 0.4982 & $3(8)$ & 0 & 0.2432 \\
\hline
\end{tabular}

$C R$ complete response, $D$-Vd daratumumab plus bortezomib/dexamethasone, ITT intent-to-treat, MRD minimal residual disease, ORR overall response rate,

$P R$ partial response, $s C R$ stringent complete response, $V d$ bortezomib/dexamethasone, $V G P R$ very good partial response

aPatients with high cytogenetic risk had a $t(4 ; 14), t(14 ; 16)$, or del17p abnormality

${ }^{\mathrm{b}}$ Response-evaluable population

$c \geq C R=s C R+C R$

$\mathrm{d}_{\geq \mathrm{VGPR}}=\mathrm{sCR}+\mathrm{CR}+\mathrm{VGPR}$

$\mathrm{ITT}$ population (standard risk: D-Vd, $n=141$; Vd, $n=140$; high risk: D-Vd, $n=40$; Vd, $n=35$ )

$P=0.0091)$ and high cytogenetic risk (15\% vs $0 \%$; $P=0.0271$; Table 3). MRD negativity was sustained for at least 6 months in a greater number of patients treated with $\mathrm{D}-\mathrm{Vd}$ versus $\mathrm{Vd}$, regardless of cytogenetic risk status. MRD negativity was sustained for at least 12 months in $2(1 \%)$ patients with standard cytogenetic risk and 3 (8\%) patients with high cytogenetic risk in the $\mathrm{D}-\mathrm{Vd}$ group compared with none in both cytogenetic risk categories in the Vd group.

Median PFS2 was prolonged with D-Vd compared with $\mathrm{Vd}$ in the standard cytogenetic risk (34.2 months vs 18.5 months; HR, 0.41; 95\% CI, 0.30-0.58; $P<0.0001$; Fig. 2a) and high cytogenetic risk (28.1 months vs 19.7 months; HR, 0.58; 95\% CI, 0.30-1.10; $P=0.0915$; Fig. 2b) subgroups. Among the subset of patients with 1 prior line of therapy, median PFS2 was prolonged with $\mathrm{D}-\mathrm{Vd}$ versus $\mathrm{Vd}$ in patients with standard cytogenetic risk (not estimable vs 23.4 months; HR, 0.43 ; $95 \% \mathrm{CI}, 0.26-0.72$; $P=0.0009$; Fig. 2c). For patients with high cytogenetic risk, median PFS2 was prolonged with $\mathrm{D}-\mathrm{Vd}$ versus $\mathrm{Vd}$ (34.9 months vs 25.1 months; HR, 0.54; 95\% CI, 0.21-1.39; $P=0.1951$; Fig 2d).

At the time of the analysis, among patients with high cytogenetic risk, 21 deaths were observed in the $\mathrm{D}-\mathrm{Vd}$ group versus 23 deaths in the $\mathrm{Vd}$ group. The overall survival data are immature and follow-up for overall survival is ongoing.

\section{Updated safety results}

The most frequent any grade treatment-emergent adverse events observed in at least $25 \%$ of patients and the most frequent grade $3 / 4$ treatment-emergent adverse events observed in at least $5 \%$ of patients are summarized in Table 4. Treatment discontinuation rates due to treatment-emergent adverse events were similar between treatment groups for patients with standard cytogenetic risk $(11[8 \%]$ patients in the D-Vd group and 14 [10\%] of patients in the $\mathrm{Vd}$ group) and among patients with high cytogenetic risk (4 [10\%] patients in the $\mathrm{D}-\mathrm{Vd}$ group and 3 [9\%] patients in the Vd group).

\section{Discussion}

After a median follow-up of more than 3 years, D-Vd continued to demonstrate substantially improved efficacy in terms of PFS compared with Vd alone in patients with RRMM, regardless of cytogenetic risk status. D-Vd reduced the risk of disease progression or death by $74 \%$ versus $\mathrm{Vd}$ alone in patients with standard cytogenetic risk and by $59 \%$ in patients with high cytogenetic risk. Among patients treated with $\mathrm{D}-\mathrm{Vd}$, median PFS was 16.6 months in patients with standard cytogenetic risk (vs 6.6 months with Vd; $P<0.0001)$ and 12.6 months in patients with high cytogenetic risk (vs 6.2 months with Vd; $P=0.0106$ ). The PFS benefit of D-Vd over Vd was especially pronounced in the subset of patients who received 1 prior line of therapy, reducing the risk of disease progression or death by $75 \%$ and $80 \%$ in patients with standard and high cytogenetic risk, respectively. D-Vd achieved deep responses compared with $\mathrm{Vd}$, with higher rates of VGPR or better and CR or better, regardless of cytogenetic risk status. Rates of MRD 


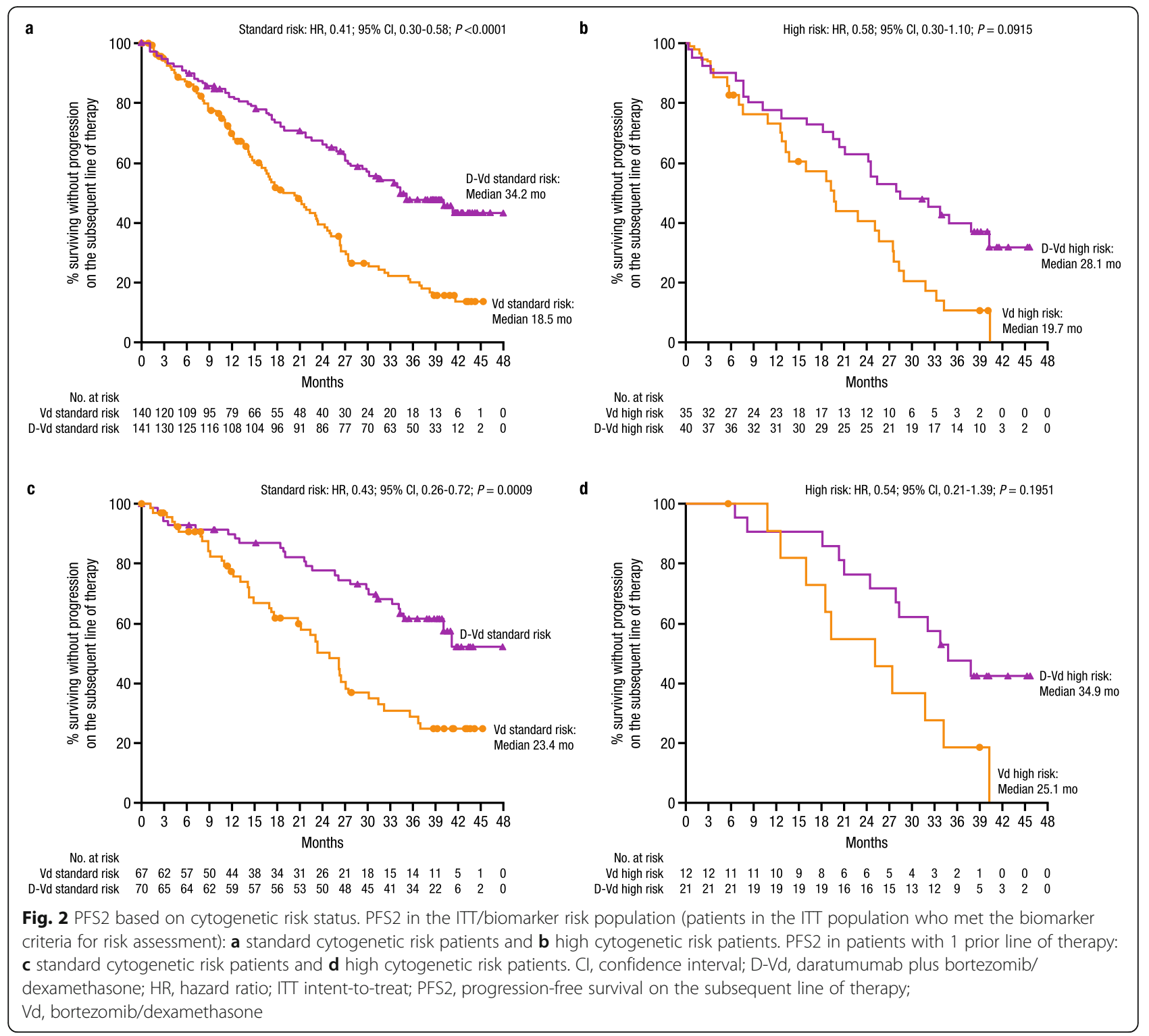

negativity $\left(10^{-5}\right.$ sensitivity threshold) were higher with $\mathrm{D}-\mathrm{Vd}$ versus $\mathrm{Vd}$ in patients with standard cytogenetic risk $(11 \%$ vs $3 \% ; P=0.0091)$ and high cytogenetic risk $(15 \%$ vs $0 \% ; P=0.0271)$. Moreover, sustained MRD-negative responses were observed in more patients treated with $\mathrm{D}-\mathrm{Vd}$ compared with $\mathrm{Vd}$ regardless of cytogenetic risk status. D-Vd prolonged median PFS2 versus Vd alone in both cytogenetic risk subgroups. Overall, improved outcomes were achieved by $\mathrm{D}-\mathrm{Vd}$ versus $\mathrm{Vd}$ in patients with high cytogenetic risk, but clinical benefits were of lesser magnitude than $\mathrm{D}-\mathrm{Vd}$ in patients with standard cytogenetic risk.

The safety profile of D-Vd in standard and high cytogenetic risk subgroups was consistent with the overall population of CASTOR. No new safety signals were identified.
The results reported here after extended follow-up further strengthen results reported after a median followup of 13.0 months [18]. In this earlier analysis in patients with high cytogenetic risk, PFS was prolonged with $\mathrm{D}-\mathrm{Vd}$ versus Vd (median 11.2 months vs 7.2 months; HR, 0.49; 95\% CI, 0.27-0.89; $P=0.0167$ ). With a median follow-up of 40.0 months, the efficacy of $\mathrm{D}-\mathrm{Vd}$ versus $\mathrm{Vd}$ in these high-risk patients was maintained, with prolonged median PFS (HR, 0.41) and higher MRD-negativity rates $(15 \%$ vs $0 \% ; P=0.0271)$ in this difficult-to-treat patient population.

While cross-trial comparisons should be approached with caution, especially due to lack of consensus on thresholds for risk groups, the efficacy of D-Vd in patients with high cytogenetic risk appears favorable to that reported in other studies of proteasome inhibitor- 
Table 4 Most common any-grade ( $\geq 25 \%$ of patients) and grade $3 / 4$ ( $\geq 5 \%$ of patients) TEAEs

\begin{tabular}{|c|c|c|c|c|c|c|c|c|}
\hline \multirow[b]{3}{*}{ TEAE, $n(\%)$} & \multicolumn{4}{|c|}{ Any grade } & \multicolumn{4}{|c|}{ Grade $3 / 4$} \\
\hline & \multicolumn{2}{|c|}{ Standard risk } & \multicolumn{2}{|c|}{ High risk $^{a}$} & \multicolumn{2}{|c|}{ Standard risk } & \multicolumn{2}{|c|}{ High risk $^{a}$} \\
\hline & $\begin{array}{l}\mathrm{D}-\mathrm{Vd} \\
(n=137)\end{array}$ & $\begin{array}{l}\mathrm{Vd} \\
(n=136)\end{array}$ & $\begin{array}{l}\text { D-Vd } \\
(n=40)\end{array}$ & $\begin{array}{l}\mathrm{Vd} \\
(n=34)\end{array}$ & $\begin{array}{l}\text { D-Vd } \\
(n=137)\end{array}$ & $\begin{array}{l}\mathrm{Vd} \\
(n=136)\end{array}$ & $\begin{array}{l}\mathrm{D}-\mathrm{Vd} \\
(n=40)\end{array}$ & $\begin{array}{l}\mathrm{Vd} \\
(n=34)\end{array}$ \\
\hline \multicolumn{9}{|l|}{ Hematologic } \\
\hline Thrombocytopenia & $85(62)$ & $58(43)$ & $24(60)$ & $16(47)$ & $65(47)$ & $45(33)$ & $19(48)$ & $12(35)$ \\
\hline Anemia & $45(33)$ & $41(30)$ & $7(18)$ & $14(41)$ & $25(18)$ & $23(17)$ & $4(10)$ & $6(18)$ \\
\hline Neutropenia & $29(21)$ & $16(12)$ & $9(23)$ & $3(9)$ & $21(15)$ & $6(4)$ & $6(15)$ & $2(6)$ \\
\hline Lymphopenia & $18(13)$ & $5(4)$ & $4(10)$ & $4(12)$ & $14(10)$ & $3(2)$ & $3(8)$ & $3(9)$ \\
\hline Leukopenia & $15(11)$ & $5(4)$ & $3(8)$ & $3(9)$ & $5(4)$ & $1(1)$ & $1(3)$ & $2(6)$ \\
\hline \multicolumn{9}{|l|}{ Nonhematologic } \\
\hline Peripheral sensory neuropathy & $67(49)$ & $50(37)$ & $22(55)$ & $13(38)$ & $4(3)$ & $8(6)$ & $2(5)$ & $4(12)$ \\
\hline Upper respiratory tract infection & $43(31)$ & $20(15)$ & $15(38)$ & $8(24)$ & $1(1)$ & 0 & $3(8)$ & $1(3)$ \\
\hline Diarrhea & $42(31)$ & $35(26)$ & $11(28)$ & $6(18)$ & $6(4)$ & $2(2)$ & $1(3)$ & 0 \\
\hline Cough & $40(29)$ & $19(14)$ & $9(23)$ & $4(12)$ & 0 & 0 & 0 & 0 \\
\hline Fatigue & $25(18)$ & $40(29)$ & $17(43)$ & $8(24)$ & $6(4)$ & $5(4)$ & $2(5)$ & $1(3)$ \\
\hline Back pain & $24(18)$ & $15(11)$ & $13(33)$ & $1(3)$ & $3(2)$ & 0 & $1(3)$ & 0 \\
\hline Insomnia & $22(16)$ & $20(15)$ & $11(28)$ & $5(15)$ & $2(2)$ & 0 & 0 & $1(3)$ \\
\hline Pneumonia & $22(16)$ & $20(15)$ & $5(13)$ & $4(12)$ & $15(11)$ & $14(10)$ & $2(5)$ & $3(9)$ \\
\hline Asthenia & $15(11)$ & $19(14)$ & $4(10)$ & $9(27)$ & $1(1)$ & $3(2)$ & 0 & $1(3)$ \\
\hline Hypertension & $15(11)$ & $5(4)$ & $4(10)$ & $1(3)$ & $9(7)$ & $1(1)$ & $2(5)$ & 0 \\
\hline Decreased appetite & $14(10)$ & $8(6)$ & $10(25)$ & $1(3)$ & 0 & $1(1)$ & $1(3)$ & 0 \\
\hline Spinal pain & $4(3)$ & $3(2)$ & $2(5)$ & 0 & $1(1)$ & 0 & $2(5)$ & 0 \\
\hline Gastroenteritis & $2(2)$ & $3(2)$ & $2(5)$ & $1(3)$ & 0 & $2(2)$ & $2(5)$ & $1(3)$ \\
\hline $\begin{array}{l}\text { Squamous cell carcinoma of } \\
\text { the skin }\end{array}$ & 0 & 0 & $2(5)$ & 0 & 0 & 0 & $2(5)$ & 0 \\
\hline
\end{tabular}

TEAE treatment-emergent adverse event, $D$-Vd daratumumab/bortezomib/dexamethasone, $V d$ bortezomib/dexamethasone

${ }^{a}$ Patients with high cytogenetic risk had a $t(4 ; 14), t(14 ; 16)$, or del17p abnormality

containing regimens in RRMM (Table 5). In a preplanned subgroup analysis of the ENDEAVOR study based on baseline cytogenetic risk, carfilzomib in combination with dexamethasone reduced the risk of disease progression or death by $35 \%$ versus $\mathrm{Vd}$ in patients with high-risk RRMM (defined as $\mathrm{t}[4 ; 14]$ or $\mathrm{t}[14 ; 16]$ in $\geq 10 \%$ of screened plasma cells or del17p in $\geq 20 \%$ of screened plasma cells assessed by FISH) [19]. Median PFS was 8.8 months with carfilzomib in combination with dexamethasone versus 6.0 months with $\mathrm{Vd}$ in patients with high cytogenetic risk (HR, 0.65; 95\% CI, 0.45-0.92; $P=0.0075)$ and CR or better rates were $16 \%$ versus $4 \%$, respectively. In a pre-planned subgroup analysis of the phase 3 ASPIRE study, among patients with high

Table 5 Summary of median PFS of high cytogenetic risk patients with RRMM in randomized, phase 3 trials

\begin{tabular}{|c|c|c|c|c|c|c|}
\hline Trial name & High cytogenetic risk definition & Arm $1(n)$ & $\begin{array}{l}\text { Arm } \\
2(n)\end{array}$ & $\begin{array}{l}\text { Arm } 1 \text { median } \\
\text { PFS, months }\end{array}$ & $\begin{array}{l}\text { Arm } 2 \text { median } \\
\text { PFS, months }\end{array}$ & $\begin{array}{l}\text { Hazard ratio } \\
(95 \% \mathrm{Cl}) ; \\
P \text { value }\end{array}$ \\
\hline CASTOR & $\mathrm{t}(4 ; 14), \mathrm{t}(14 ; 16)$, or del17p assessed by FISH or karyotyping & $\mathrm{D}-\mathrm{Vd}(40)$ & $\begin{array}{l}V d \\
(35)\end{array}$ & 12.6 & 6.2 & $\begin{array}{l}0.41(0.21-0.83) ; \\
0.0106\end{array}$ \\
\hline $\begin{array}{l}\text { ENDEAVOR } \\
{[19]}\end{array}$ & $\begin{array}{l}\mathrm{t}(4 ; 14) \text { or } \mathrm{t}(14 ; 16) \text { in } \geq 10 \% \text { of screened plasma cells or del17p } \\
\text { in } \geq 20 \% \text { of screened plasma cells assessed by FISH }\end{array}$ & $\mathrm{Kd}(97)$ & $\begin{array}{l}V d \\
(113)\end{array}$ & 8.8 & 6.0 & $\begin{array}{l}0.65(0.45-0.92) ; \\
0.0075\end{array}$ \\
\hline ASPIRE [20] & $\begin{array}{l}\mathrm{t}(4 ; 14), \mathrm{t}(14 ; 16) \text {, or del17p (in } \geq 60 \% \text { of screened plasma cells) } \\
\text { assessed by FISH }\end{array}$ & KRd (48) & $\begin{array}{l}\mathrm{Rd} \\
(52)\end{array}$ & 23.1 & 13.9 & $\begin{array}{l}0.70(0.43-1.16) ; \\
0.0829\end{array}$ \\
\hline $\begin{array}{l}\text { PANORAMA-1 } \\
{[21]}\end{array}$ & $\mathrm{t}(4 ; 14), \mathrm{t}(14 ; 16)$, or del17p assessed by FISH & $\begin{array}{l}\text { Panobinostat } \\
\text { plus Vd }\end{array}$ & $\mathrm{Vd}$ & - & - & $0.47(0.18-1.25)$ \\
\hline
\end{tabular}


cytogenetic risk ( $\mathrm{t}[4 ; 14], \mathrm{t}[14 ; 16]$, or del17p in $\geq 60 \%$ of screened plasma cells assessed by FISH), median PFS was 23.1 months with carfilzomib plus Rd versus 13.9 months with $\mathrm{Rd}$ alone (HR, 0.70; 95\% CI, 0.43-1.16; $P=0.0829$ ) [20]. In the phase 3 PANORAMA-1 trial of panobinostat plus $\mathrm{Vd}$ versus $\mathrm{Vd}$ alone in RRMM, the HR for median PFS in high-risk patients ( $\mathrm{t}[4 ; 14]$, $\mathrm{t}[14 ; 16]$, or del17p assessed by FISH) was 0.47 (95\% CI, $0.18-1.25)$ in favor of panobinostat-Vd [21].

The efficacy of daratumumab plus standard of care, regardless of cytogenetic risk status, was also demonstrated in the phase 3 POLLUX study of daratumumab plus Rd versus Rd alone in RRMM [22]. At a median follow-up of more than 3 years, median PFS was prolonged with daratumumab plus Rd (D-Rd) versus $\mathrm{Rd}$ in patients with standard (not reached vs 19.9 months; HR, $0.41 ; 95 \%$ CI, $0.31-0.55 ; P<0.0001)$ and high (26.8 vs 8.8 months; HR, $0.54 ; 95 \%$ CI, 0.32-0.91; $P=0.0175)$ cytogenetic risk, and deep responses were achieved with D-Rd in both cytogenetic risk subgroups. It is noteworthy that D-Vd and D-Rd, but not Vd nor Rd, achieved MRD negativity in patients with high cytogenetic risk, which suggests that targeting CD38 in combination with other standard of care regimens helps improve the historically poor outcomes observed in this patient population [23-27]. Looking ahead, there continues to be a gap in treatment options for high-risk patients with RRMM; potential treatment regimens that can be studied include daratumumab in combination with pomalidomide, carfilzomib, or bortezomib, lenalidomide, and dexamethasone.

This report is limited by incomplete cytogenetic abnormality data collected for patients enrolled in the CASTOR study; cytogenetic testing was not performed in $29 \%$ of patients in the study. Cytogenetic testing was performed locally and no per-protocol specific cut-off values were used for defining the presence of genetic abnormalities; cut-off values used at each site were not collected. Additionally, MRD was not assessed in patients with VGPR and in $16 \%$ of patients with CR or better. Of patients with available cytogenetic abnormality data, patients without MRD assessment were considered MRD positive, potentially underestimating the rate of MRD negativity. Lastly, small sample sizes in the cytogenetic risk subgroups precluded us from conducting a multivariate analysis to account for baseline differences.

\section{Conclusions}

In this subgroup analysis, D-Vd demonstrated a clear efficacy benefit compared with Vd in patients with RRMM and high cytogenetic risk in CASTOR. When combined with the recently updated POLLUX results, these findings reinforce the effectiveness and tolerability of daratumumab plus standard of care as a treatment for MM, regardless of cytogenetic risk status.

\begin{abstract}
Abbreviations
Cl: Confidence interval; CR: Complete response; D-Rd: Daratumumab plus lenalidomide/dexamethasone; D-Vd: Daratumumab plus bortezomib/ dexamethasone; FISH: Fluorescence in situ hybridization; HR: Hazard ratio; ITT: Intent-to-treat; MRD: Minimal residual disease; MM: Multiple myeloma; PFS: Progression-free survival; PFS2: Progression-free survival on the subsequent line of therapy; Rd: Lenalidomide/dexamethasone; RRMM: Relapsed or refractory multiple myeloma; Vd: Bortezomib/ dexamethasone; VGPR: Very good partial response
\end{abstract}

\section{Acknowledgments \\ The authors would like to thank the patients who participated in this study and their families, as well as the study co-investigators, research nurses, and coordinators at each of the clinical sites. The authors thank Maria Krevvata, PhD, of Janssen Research \& Development, LLC, for contributions to the study. Medical writing and editorial support were provided by Kristin Runkle, PhD, of MedErgy, and were funded by Janssen Global Services, LLC.}

\section{Authors' contributions}

$V H, W B, A A C-K, M B, H A$, and $M-V M$ designed the research study, acquired and analyzed the data, drafted the manuscript, and approved the final version. ND designed the research study, analyzed the data, drafted the manuscript, and approved the final version. KW and PS designed the research study, drafted the manuscript, and approved the final version. SL, TMM, IS, AB, HQ, MM, CL, MCavo, JU, and RK acquired and analyzed the data, drafted the manuscript, and approved the final version. TM, BL, M-DL, J-JL, C-KM, NH, RO, J-CJ, and H-JS acquired the data, drafted the manuscript, and approved the final version. AS, HA-L, MCapra, AN, PC, and TC analyzed the data, drafted the manuscript, and approved the final version.

\section{Funding}

This CASTOR study was sponsored by Janssen Research \& Development, LLC. Open access funding provided by Projekt DEAL.

\section{Availability of data and materials}

The data sharing policy of Janssen Pharmaceutical Companies of Johnson \& Johnson is available at https://www.janssen.com/clinical-trials/transparency. As noted on this site, requests for access to the study data can be submitted through Yale Open Data Access (YODA) Project site at http://yoda.yale.edu.

\section{Ethics approval and consent to participate}

The study protocol was approved by an independent ethics committee or institutional review board at each study center and was conducted in accordance with the principles of the Declaration of Helsinki and the International Conference on Harmonisation Good Clinical Practice guidelines. All patients provided written informed consent.

\section{Consent for publication}

Not applicable.

\section{Competing interests}

KW received honoraria from GlaxoSmithKline, Sanofi, Adaptive, Amgen, Bristol-Myers Squibb, Celgene, Janssen, and Takeda; served in a consulting or advisory role for GlaxoSmithKline, Amgen, Adaptive, Bristol-Myers Squibb, Celgene, Janssen, Takeda, Sanofi, and Juno; and received institutional research funding from Amgen, Celgene, Sanofi, and Janssen. AS received honoraria from Celgene, Janssen, Amgen, AbbVie, Servier, and Takeda; served in a consulting or advisory role for Celgene, Janssen, Servier, and AbbVie; and served on a speakers bureau for and received institutional funding from Janssen, Takeda, and Celgene. SL holds stock and patents, royalties, or other intellectual property from Caelum Biosciences; served in a consulting or advisory role for Caelum Biosciences, Takeda, Janssen, Celgene, Bristol-Myers Squibb, AbbVie, and Bayer; received research funding from Sanofi; declared another relationship with Clinical Care Options; and served on data safety monitoring boards for Sorrento and Bayer. TMM holds stock in AbbVie; received honoraria and research funding from Celgene; and served in a consulting or advisory role for Janssen, Takeda, and Adaptive. M-DL is a consultant for and receives honoraria and travel support from AbbVie, Celgene, Amgen, and Janssen. AB received honoraria from Amgen; served in a consulting or advisory role for Takeda; and had travel, accommodations, or other expenses paid or reimbursed by Celgene, Janssen, and Amgen. VH served in a consulting or advisory role and on a speakers bureau for AbbVie, 
Amgen, Celgene, Janssen, Takeda, and Bristol-Myers Squibb. MCavo received honoraria from Celgene, Janssen, Amgen, Bristol-Myers Squibb, AbbVie, and Takeda; served in a consulting or advisory role for Janssen, Celgene, Amgen, and AbbVie; and served on a speakers bureau for and had travel, accommodations, or other expenses paid or reimbursed by Janssen and Celgene. AN received honoraria from and served in a consulting or advisory role for Janssen, GlaxoSmithKline, Celgene, Amgen, Takeda, Spectrum, Bristol-Myers Squibb, Karyopharm, Oncopeptides, and Adaptive and received research funding from Janssen, GlaxoSmithKline, Celgene, Amgen, Takeda, Karyopharm, and Bristol-Myers Squibb. HQ served in a consulting or advisory role for Celgene, Amgen, Karyopharm, and GlaxoSmithKline and received research funding from Celgene and Amgen. MM received honoraria from Janssen, Bristol-Myers Squibb, Celgene, and Amgen; served in a consulting or advisory role for Janssen, Bristol-Myers Squibb, Takeda, Celgene, Amgen, and Heidelberg Pharma; received research funding from Incyte and Bristol-Myers Squibb; and had travel, accommodations, or other expenses paid or reimbursed by Janssen, Bristol-Myers Squibb, Takeda, Celgene, and Amgen. CL received honoraria from and consulted for Amgen, Janssen-Cilag, Takeda, and Celgene. PC received honoraria from Daiichi Sankyo, Kite, KiowaKirin, Celgene, Janssen, Novartis, Roche, Takeda, Sanofi, Amgen, Gilead, and AbbVie and had travel, accommodations, or other expenses paid or reimbursed by Novartis, Janssen, Celgene, Bristol-Myers Squibb, Takeda, Gilead, Amgen, and AbbVie. AAC-K received research funding from the Mayo Clinic. NH served on the board of directors or advisory committees for Janssen. MCapra received honoraria from AbbVie, GlaxoSmithKline, Bristol-Myers Squibb, Adaptive, Takeda, Janssen, and Celgene. MB served in a consulting or advisory role and on a speakers bureau for Amgen, Janssen, and Takeda. RO consulted for Janssen. PS received honoraria from and research funding from Amgen, Celgene, Janssen, SkylineDx, and Takeda. TC is an employee of Janssen and holds stock options from Johnson \& Johnson. ND, HA, JU, and RK are employees of Janssen. M-VM received honoraria from and served in a consulting or advisory role for Janssen, Celgene, Amgen, Takeda, GlaxoSmithKline, AbbVie, Seattle Genetics, and Adaptive. HA-L, IS, TM, BL, J$J$, WB, C-KM, J-CJ, and H-JS have no conflicts of interest to disclose.

\section{Author details}

'Department of Oncology, Hematology and Bone Marrow Transplantation with Section of Pneumology, University Medical Center Hamburg-Eppendorf, Hamburg, Germany. ${ }^{2}$ Malignant Haematology and Stem Cell Transplantation Service, Alfred Health-Monash University, Melbourne, Australia. ${ }^{3}$ Division of Hematology/Oncology, Columbia University, New York, NY, USA. ${ }^{4}$ Unite de Genomique du Myelome, CHU Rangueil, Toulouse, France. ${ }^{5}$ Department of Medicine, University of Colorado, Aurora, CO, USA. ${ }^{6}$ Clinical Department of Haematology, 1st Medical Department, Charles University in Prague, Prague, Czech Republic. 'ászló Hospital, 3rd Department of Internal Medicine, Semmelweis University, Budapest, Hungary. ${ }^{8}$ Department of Hematology, Sunderbyn Hospital, Luleå, Sweden. ${ }^{9}$ Department of Internal Medicine, Albert Schweitzer Hospital, Dordrecht, The Netherlands. ${ }^{10}$ Department of Hematology, Careggi Hospital and University of Florence, Firenze, Italy. ${ }^{11}$ Irmandade Da Santa Casa De Misericordia De São Paulo, São Paulo, Brazil. 12"Seràgnoli" Institute of Hematology, Department of Experimental, Diagnostic and Specialty Medicine, University of Bologna, Bologna, Italy. ${ }^{13}$ Department of Hematology-Oncology, Chonnam National University Hwasun Hospital, Hwasun, Jeollanamdo, South Korea. ${ }^{14}$ Winship Cancer Institute, Emory University, Atlanta, GA, USA. ${ }^{15}$ University of Melbourne, St Vincent's Hospital, Melbourne, Australia. ${ }^{16}$ University Medical Center of the Johannes Gutenberg University, Third Department of Medicine, Mainz, Germany. ${ }^{17}$ Royal Adelaide Hospital, North Terrace, Adelaide, Australia. ${ }^{18}$ University of São Paulo, Ribeirão Preto, Brazil. ${ }^{19}$ Fondazione IRCCS Istituto Nazionale dei Tumori, University of Milan, Milan, Italy. ${ }^{20}$ Seoul St. Mary's Hospital, Seoul, South Korea. ${ }^{21}$ Mayo Clinic Florida, Jacksonville, FL, USA. ${ }^{22}$ Instituto do Cancer-Hospital Mae de Deus, Porto Alegre, Brazil. ${ }^{23}$ Ankara University, Ankara, Turkey. ${ }^{24}$ Hospital Angeles Lomas, Naucalpan de Juárez y alrededores, Mexico. ${ }^{25}$ Ulsan University Hospital, Ulsan, South Korea. ${ }^{26}$ Department of Internal Medicine, Pusan National University Hospital, Busan, South Korea. ${ }^{27}$ Erasmus MC, Rotterdam, The Netherlands. ${ }^{28}$ Janssen Research \& Development, LLC, Beerse, Belgium. ${ }^{29}$ Janssen Research \& Development, LLC, Spring House, PA, USA. ${ }^{30}$ Janssen Research \& Development, LLC, Raritan, NJ, USA. ${ }^{31}$ Janssen Global Scientific Affairs, Horsham, PA, USA. ${ }^{32}$ University Hospital of Salamanca/IBSAL/Cancer Research Center-IBMCC (USAL-CSIC), Salamanca, Spain.
Received: 8 April 2020 Accepted: 30 July 2020

Published online: 20 August 2020

\section{References}

1. de Weers M, Tai YT, van der Veer MS, Bakker JM, Vink T, Jacobs DC, et al. Daratumumab, a novel therapeutic human CD38 monoclonal antibody, induces killing of multiple myeloma and other hematological tumors. J Immunol. 2011;186(3):1840-8.

2. Lammerts van Bueren J, Jakobs D, Kaldenhoven N, Roza M, Hiddingh S, Meesters J, et al. Direct in vitro comparison of daratumumab with surrogate analogs of CD38 antibodies MOR03087, SAR650984 and Ab79. Blood. 2014; 124(21):3474.

3. Overdijk MB, Verploegen S, Bogels M, van Egmond M, Lammerts van Bueren JJ, Mutis T, et al. Antibody-mediated phagocytosis contributes to the anti-tumor activity of the therapeutic antibody daratumumab in lymphoma and multiple myeloma. MAbs. 2015;7(2):311-21.

4. Overdijk MB, Jansen JH, Nederend M, Lammerts van Bueren JJ, Groen RW, Parren PW, et al. The therapeutic CD38 monoclonal antibody daratumumab induces programmed cell death via Fcgamma receptor-mediated crosslinking. J Immunol. 2016;197(3):807-13.

5. Krejcik J, Casneuf T, Nijhof IS, Verbist B, Bald J, Plesner T, et al. Daratumumab depletes $\mathrm{CD}_{3}{ }^{+}$immune-regulatory cells, promotes T-cell expansion, and skews T-cell repertoire in multiple myeloma. Blood. 2016;128(3):384-94.

6. Chiu C, Casneuf T, Axel A, Lysaght A, Bald J, Khokhar NZ, et al. Daratumumab in combination with lenalidomide plus dexamethasone induces clonality increase and T-cell expansion: results from a phase 3 randomized study (POLLUX). Blood. 2016;128:4531.

7. Adams HC 3rd, Stevenaert F, Krejcik J, Van der Borght K, Smets T, Bald J, et al. High-parameter mass cytometry evaluation of relapsed/refractory multiple myeloma patients treated with daratumumab demonstrates immune modulation as a novel mechanism of action. Cytometry A. 2019; 95(3):279-89.

8. DARZALEX ${ }^{\mathrm{TM}}$ (daratumumab) injection, for intravenous use [package insert]. Horsham, PA: Janssen Biotech, Inc.; 2018.

9. Palumbo A, Chanan-Khan A, Weisel K, Nooka AK, Masszi T, Beksac M, et al. Daratumumab, bortezomib, and dexamethasone for multiple myeloma. N Engl J Med. 2016;375(8):754-66.

10. Avet-Loiseau H, Casneuf T, Chiu C, Laubach JP, Lee JJ, Moreau P, et al. Evaluation of minimal residual disease (MRD) in relapsed/refractory multiple myeloma (RRMM) patients treated with daratumumab in combination with lenalidomide plus dexamethasone or bortezomib plus dexamethasone. Blood. 2016;128:246.

11. Mateos M-V, Sonneveld P, Hungria VTM, Nooka AK, Estell J, Barreto WG, et al. Efficacy and safety of daratumumab, bortezomib, and dexamethasone $(\mathrm{D}-\mathrm{Vd})$ versus bortezomib and dexamethasone $(\mathrm{Vd})$ in first relapse patients: two-year update of CASTOR. Poster presented at: 60th Annual Meeting of the American Society of Hematology; December 1-4, 2018; San Diego, CA. Abstract 3270

12. Sonneveld P, Avet-Loiseau H, Lonial S, Usmani S, Siegel D, Anderson KC, et al. Treatment of multiple myeloma with high-risk cytogenetics: a consensus of the International Myeloma Working Group. Blood. 2016; 127(24):2955-62.

13. Rajan AM, Rajkumar SV. Interpretation of cytogenetic results in multiple myeloma for clinical practice. Blood Cancer J. 2015;5:e365.

14. Fonseca R, Bergsagel PL, Drach J, Shaughnessy J, Gutierrez N, Stewart AK, et al. International Myeloma Working Group molecular classification of multiple myeloma: spotlight review. Leukemia. 2009;23(12):2210-21.

15. Spencer A, Lentzsch S, Weisel K, Avet-Loiseau H, Mark TM, Spicka I, et al. Daratumumab plus bortezomib and dexamethasone versus bortezomib and dexamethasone in relapsed or refractory multiple myeloma: updated analysis of CASTOR. Haematologica. 2018;103(12):2079-87.

16. Durie BGM, Harousseau JL, Miguel JS, Blade J, Barlogie B, Anderson K, et al. International uniform response criteria for multiple myeloma. Leukemia. 2006;20(9):1467-73.

17. Rajkumar SV, Harousseau JL, Durie B, Anderson KC, Dimopoulos M, Kyle R, et al. Consensus recommendations for the uniform reporting of clinical trials: report of the International Myeloma Workshop Consensus Panel 1. Blood. 2011;117(18):4691-5.

18. Mateos MV, Estell J, Barreto W, Corradini P, Min CK, Medvedova E, et al., editors. Efficacy of daratumumab, bortezomib, and dexamethasone versus bortezomib and dexamethasone in relapsed or refractory myeloma based 
on prior lines of therapy: updated analysis of CASTOR. Presented at the 58th Annual Meeting \& Exposition of the American Society of Hematology (ASH); December 3-6, 2016; San Diego, CA Abstract 1150; 2016.

19. Chng WJ, Goldschmidt H, Dimopoulos MA, Moreau P, Joshua D, Palumbo A, et al. Carfilzomib-dexamethasone vs bortezomib-dexamethasone in relapsed or refractory multiple myeloma by cytogenetic risk in the phase 3 study ENDEAVOR. Leukemia. 2016;31(6):1368-74.

20. Avet-Loiseau H, Fonseca R, Siegel D, Dimopoulos MA, Spicka I, Masszi T, et al. Carfilzomib significantly improves the progression-free survival of high-risk patients in multiple myeloma. Blood. 2016;128(9):1174-80.

21. San-Miguel JF, Hungria VT, Yoon SS, Beksac M, Dimopoulos MA, Elghandour A, et al. Panobinostat plus bortezomib and dexamethasone versus placebo plus bortezomib and dexamethasone in patients with relapsed or relapsed and refractory multiple myeloma: a multicentre, randomised, double-blind phase 3 trial. Lancet Oncol. 2014;15(11):1195-206.

22. Kaufman JL, Dimopoulos MA, Leiba M, Morton J, Ho PJ, Kim K, et al. Efficacy and safety of daratumumab, lenalidomide, and dexamethasone (D-Rd) in relapsed or refractory multiple myeloma (RRMM): updated subgroup analysis of POLLUX based on cytogenetic risk. J Clin Oncol. 2019;37(suppl): Abstract 8038

23. Dimopoulos MA, Weisel KC, Song KW, Delforge M, Karlin L, Goldschmidt $H_{\text {, }}$ et al. Cytogenetics and long-term survival of patients with refractory or relapsed and refractory multiple myeloma treated with pomalidomide and low-dose dexamethasone. Haematologica. 2015;100(10):1327-33.

24. Avet-Loiseau H, Attal M, Moreau P, Charbonnel C, Garban F, Hulin C, et al. Genetic abnormalities and survival in multiple myeloma: the experience of the Intergroupe Francophone du Myelome. Blood. 2007;109(8):3489-95.

25. Avet-Loiseau H, Hulin C, Campion L, Rodon P, Marit G, Attal M, et al. Chromosomal abnormalities are major prognostic factors in elderly patients with multiple myeloma: the Intergroupe Francophone du Myelome experience. J Clin Oncol. 2013;31(22):2806-9.

26. Chng WJ, Dispenzieri A, Chim CS, Fonseca R, Goldschmidt H, Lentzsch S, et al. IMWG consensus on risk stratification in multiple myeloma. Leukemia. 2014;28(2):269-77.

27. Sawyer JR. The prognostic significance of cytogenetics and molecular profiling in multiple myeloma. Cancer Gene Ther. 2011;204(1):3-12.

\section{Publisher's Note}

Springer Nature remains neutral with regard to jurisdictional claims in published maps and institutional affiliations.

Ready to submit your research? Choose BMC and benefit from:

- fast, convenient online submission

- thorough peer review by experienced researchers in your field

- rapid publication on acceptance

- support for research data, including large and complex data types

- gold Open Access which fosters wider collaboration and increased citations

- maximum visibility for your research: over $100 \mathrm{M}$ website views per year

At $\mathrm{BMC}$, research is always in progress.

Learn more biomedcentral.com/submissions 